\title{
Recombinant Sip Young 6 His Protein Production from the Sea Star Igkappa Gene, after Cloning
}

\author{
Michel Leclerc
}

\section{ABSTRACT}

In 2014 we have isolated and cloned the sea star Igkappa gene which induced an anti-HRP primitive invertebrate antibody. We attempt, in the present work, for the first time in Invertebrates, to produce a SIP Young 6 His protein through HeK 293 EBNA cells.

Published Online: April 12, 2021

ISSN: 2684-5199

DOI: $10.24018 /$ ejbio.2021.2.2.175

Keywords: Invertebrates; HEK 293 cells; sea star Igkappa gene; Asterias rubens.

\section{INTRODUCTION}

The sea star IGKappa gene was discovered in 2014 [1]. It is an IPA (Invertebrate Primitive Antibody) which produce an anti-HRP protein. We recall it was obtained from sea star Asterias rubens immunized to HRP (Horse-radish peroxydase). In 2014 [2] it was inserted in an Escherichia coli plasmid and showed a specific binding to the antigen HRP [2].

In the present time we attempt to use another "carrier" to express this protein: The Hek 293 EBNA cells.

\section{MATERIALS AND MEthodS}

\section{A. Subcloning in Expression Vector}

The genes coding for the target proteins were chemically synthesized with optimization for expression in HEK293 cells. The sequence is illustrated below [1].

\section{B. Sequences Information}

> SIP_Young_6His cDNA - 384 bp

ATGGGCGGAATGAGAGGCAACATGGCCAGCCTG TGGATGTTCTTTTTCGTGGTGGGCATCACACTGCAG AGGAGC

CTGGCCATCTACACATTCAGAGAGCAGCCTTCCG ACACCTCCGCCCTGCAGGGCAGCACAGTGGTGCTG CACTGT

AGCGTGGAGCAGTACATCAACACCACCGCCATC GTGTGGTGGAGCAGGGATTCCGTGATCTCCCACAA CAACGAC CTGAACCTGAGCAGCCTGAACACAGATCAGCTGCA GAGCTACAGCATCAGCGGCGACGCCTCCAGGGGCG AGTTC
CGCCAGCTACAGATGTCAGATGCTGGAGCACCACC ACCAC

CATCACTGA

Expected protein sequence

> SIP_Young_6His - 127 AAs - 14.30 kDa

MGGMRGNMASLWMFFFVVGITLQRSLAIYTFREQ PSDTSALQGSTVVLHCSVEQYINTTAIVWWSRDSVIS HNND

LNLSSLNTDQLQSYSISGDASRGEFNLNIVNFTATD

AASYRCQMLEHHHHHH Features:

SIP: [1:27]

His tag [122:127].

\section{RESULTS}

Small-scale Expression and Purification Tests

\section{A. Short Protocol Description}

The pTXs 2 construction obtained as described in $\$ 2$ were transfected in HEK293 cells $(80 \mathrm{ml}$ culture) by using NeoBiotech's proprietary Xten transient transfection protocol. Culture medium and cell samples were collected until viability drops under $50 \%$ post-transfection. $1.5 \mathrm{ml} \mathrm{Cell}$ culture were collected, followed by semi-purification with $\mathrm{Ni}$ resin and SDS-PAGE with WB analysis. The results are illustrated below.

Reduced SDS-PAGE analysis after sonication of cells, then western-blots were obtained in Fig. 1.

It shows that the protein has a molecular weight of about $14 \mathrm{Kd}$ after denaturation in PBS pH 7.5 with urea $8 \mathrm{M}$. 


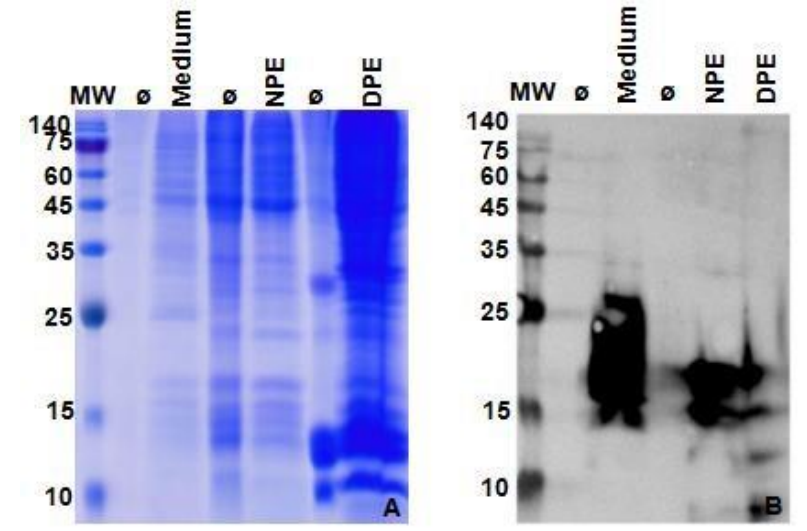

Fig. 1. Expression test result.

A - Reduced SDS-PAGE analysis. Coomassie blue staining.

B - Western blot with anti-his antibody (ECL revelation).

ø. Negative control culture. Medium: Analysis of the culture medium.

NPE: Native protein extracts obtained by cell lysis (sonication) in native buffer (PBS pH 7.5).

DPE: Denatured protein extracts prepared by solubilization of the pellet obtained after the native lysis in a denaturing buffer (PBS pH 7.5 with urea $8 \mathrm{M})$.

\section{B. Short Purification Protocol Description}

Culture medium was purified by affinity against His-tag (IMAC) by a standard method:

- Equilibration with PBS, pH 7.5

- Wash 1/2/3 with PBS, pH 7.5, 0 mM, $30 \mathrm{mM}$ and $50 \mathrm{mM}$ imidazole buffer

- Elution with PBS, pH 7.5, $200 \mathrm{mM}$ and $400 \mathrm{mM}$ imidazole buffer

- Analysis by SDS-PAGE of fractions of interest

- Final sample QC: qualitative by SDS-PAGE, quantitative by Bradford method

E2-E6 were pooled, buffer exchanged vs PBS, $\mathrm{pH} 7.5$ by dialysis method. The purification test results, and QC are illustrated in Fig. 2 and Fig. 3.
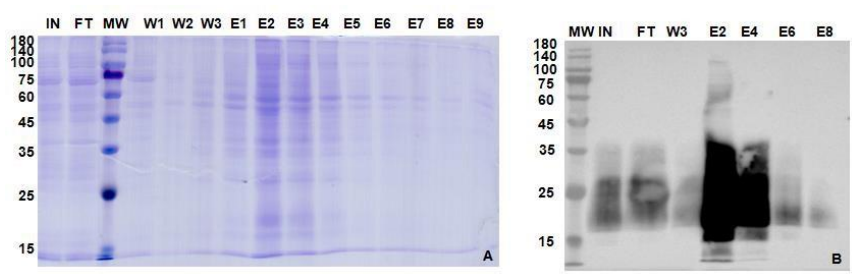

Fig. 2. Target protein purification profile. Coomassie blue staining. A. Reduced PAGE analysis.

B. Western blot with anti-his antibody (ECL revelation). MW - Molecular weight marker. IN - Input. FT - Flow through. W1-W3 - Washes. E - Eluted fractions.

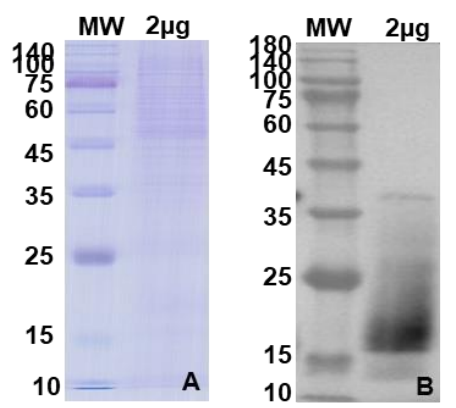

Fig. 2. The final QC gel. Coomassie blue staining. A. Reduced PAGE analysis.

B. Western blot with anti-his antibody (ECL revelation). MW. Molecular weight marker.
These figures show clearly that the eluates E2, E3, E4 contain mainly the SIP Young 6 His protein which is revelated by the anti-His antibody (ECL revelation).

\section{CONCLUSION}

We retain the following characteristics of the obtained SIP Young 6 His protein

The final buffer (PBS, pH 7.5) has a final quantity of 0.39 $\mathrm{mg}$ for a concentration of: $0.13 \mathrm{mg} / \mathrm{ml}$. We note also that the yield is: $4.88 \mathrm{mg}$ per liter of culture: that is low. But it is the first time, at our knowledge an invertebrate IGKappa gene is inserted in HeK 293 cells.

The SIP Young 6 His protein possess a great future. It constitutes the first invertebrate protein with immune properties at least in invertebrates. Currently we study its potentialities in vertebrate immune functions.

\section{REFERENCES}

[1] Vincent, N. Osteras, M. Otten, P. et al (2014) Meta gene 2:320-22.

[2] Leclerc, M. and Otten, P. (2014) S. A. J Biotechnol. 1:104-105. 